Gut, 1962, 3, 289

\title{
Larval granulomata in the liver
}

\author{
R. A. B. DRURY \\ From the Central Middlesex Hospital, London
}

EDITORIAL SYNOPSIS Granulomata due to larvae of parasites from domestic animals, usually dogs, can be found in the human liver. These may cause clinical symptoms resembling those of chronic pancreatitis or cholecystitis, and they must be distinguished from metastatic carcinoma at laparotomy.

It is not widely appreciated that parasites from domestic dogs and cats can cause larval granulomata in the human liver in England. Larvae of the dog tongue worm (Linguatula serrata) have occasionally been identified in the liver, and the round worm of the dog or cat (Toxocara canis and T. cati) can also produce visceral larval granulomata, usually in children. Linguatulid larvae have been reported as incidental findings at necropsy, and are not considered in the living patient, as up to now there has been little evidence that they are of clinical significance (Sonobe, 1927; Symmers and Valteris, 1950). Toxocara larvae can be widely disseminated in children, and larval granulomata of the retina have imitated malignant tumours, leading to enucleation of the eye (Ashton, 1960).

Four cases of fibrous larval nodules in the liver are reported here. All were found at laparotomy and were removed for histological identification. In two patients these larvae simulated metastatic carcinoma, and their true nature was of practical importance; in the other two patients there is a possibility that the larvae caused, or contributed to, symptoms ascribed to cholecystitis and pancreatitis. These cases suggest that the recognition of small parasitic larvae is not purely academic. These surgical specimens have been compared with a larger series of similar nodules found at necropsy, and the approximate incidence of larval granulomata of the liver in the Greater London area has been determined.

\section{CASE REPORTS}

CASE 1 A 62-year-old captain of police, who had lived in Zanzibar, complained of upper abdominal pain and loss of appetite for six months. A diagnosis of carcinoma of stomach was made on gastroscopy, and an abdominothoracic total gastrectomy was performed for an anaplastic adenocarcinoma of the upper half of the stomach. A small white nodule in the capsule of the liver was removed for microscopy.
The liver nodule was intact, white, and firm; it was ovoid in shape, $3 \mathrm{~mm}$. in greatest diameter, and situated in and under the capsule of the liver. The specimen was processed whole and examined in step histological sections (every fifth section). The histological structure of the specimen is described below.

Although the patient made a good recovery after gastrectomy, he deteriorated and died 11 months after operation. At necropsy, malignant peritonitis was found, but there was no secondary carcinoma or other abnormality in the liver.

CASE 2 A 75-year-old woman, a Cypriot by birth, complained of anorexia and discomfort after food. A barium meal showed a persistent constriction of the pyloric antrum that was suggestive of carcinoma. At laparotomy no primary carcinoma was found, but a mass, estimated to be $4 \mathrm{~cm}$. in diameter, was found deep in the right lobe of the liver, and a tiny white nodule on the capsule of the right lobe was excised. No other abnormality of the liver was seen, and the abdomen was closed. The patient was discharged on the twelfth day after operation. She returned to Cyprus and has not been followed up.

The specimen consisted of a small wedge of liver containing an intact spheroidal nodule, $2 \mathrm{~mm}$. in diameter, in the capsule. The nodule was hard and white, and the whole specimen was processed in the laboratory, and studied by step histological sections (every fifth section). The histological structure is described below.

CASE 3 A 49-year-old man, with no history of residence abroad, suffered from epigastric pain for many years. This was of irregular character and was not relieved by food or alkalies. There was some tenderness in the gall bladder area. A barium meal showed no abnormality, and a cholecystogram did not outline the gall bladder satisfactorily. At laparotomy a thin-walled gall bladder of normal size was found to contain some faceted calculi. There was a small white hemispherical nodule, $3 \mathrm{~mm}$. in diameter, within the capsule of the liver close to the gall bladder site. Both the gall bladder and the capsular nodule were removed. The histological structure of the gall bladder appeared to be normal; that of the white nodule in the liver is described below. The patient made a satisfactory recovery, and has not been seen again. 
CASE 4 A 43-year-old man had served in Burma between 1942 and 1945; during this time he suffered from sandfly fever, dysentery, and repeated attacks of malaria. Soon after the war he began to have nausea and epigastric pain which were partly relieved by milk. This pain persisted for 13 years, and a barium meal then showed some pyloric deformity suggestive of chronic peptic ulceration; in the region of the pancreas there were multiple small foci of calcification, thought to be pancreatic calculi or calcification due to chronic pancreatitis.

A partial gastrectomy was performed, and the pancreas was seen to be normal apart from multiple small (1 to $3 \mathrm{~mm}$.) calcified nodules in the capsule. A few small fibrous nodules were present in the capsule of the liver, and one of these was excised; the histological picture is described below. Post-operatively, the patient made an excellent recovery; radiographs of the skull and thigh showed no pathological calcification of the brain or muscles, and there was no increase in eosinophil leucocytes.

\section{HISTOLOGY}

SURGICAL SPECIMENS The four nodules removed at laparotomy have similar histological features. All consist largely of whorled hyaline fibrous tissue of considerable age, the fibres of which are arranged in a concentric pattern. In the centre of three specimens (cases 1 to 3 ) there is a cystic space, around which a few foreign body giant cells are seen in two instances (cases 1 and 3 ). The shape of the central cavity is of considerable help in histological diagnosis because the linguatulid larva is crescentic, and if the cyst can be shown to be of this shape it strongly favours a parasitic aetiology. In case 1 , no recognizable parasitic material is seen, but a crescentshaped cyst, cut in two places in the plane of section, together with a multinucleate giant cell reaction, suggests the diagnosis (Fig. 1). In cases 2 and 3 some parasitic debris is found in the centre of the nodule, and this is clearly recognizable in case 3 (Fig. 2). The demonstration of the crescentic cavity in case 1 and the presence of parasitic material in cases 2 and 3 (hooklets, remains of body rings, and spines) are reasonably convincing evidence of linguatulid larvae. The nodule of case 4 contained calcified amorphous debris, apparently parasitic, but the type of parasite could not be identified; this was the only calcified surgical specimen. The cellular reaction around these nodules is very scanty, sometimes absent; lymphocytes predcminate and no eosinophil leucocytes are present.

POST-MORTEM SPECIMENS The histological structure of the four surgical specimens has been compared with that of 21 additional nodules obtained from the liver and spleen of 18 adult patients after death. These nodules were all incidental findings in nine males and nine females, the average age being 67 years. In 10 patients the nodules were solitary; in six patients there were two or three; and in two patients more than three nodules were found.

All the post-mortem specimens have a laminated hyaline fibrous structure with central cavitation or necrosis. Parasitic material has been identified in several instances; this is fragmentary due to successive moultings or the final dissolution of the larva, but body rings, spines, and curved hooks are seen. Occasional multinucleate cells of foreign body type, and in two cases, a light eosinophil leucocyte reaction around the nodule, confirm the exogenous parasitic aetiology. In some nodules there is a granulomatous tuberculoid tissue reaction with histiocytes around central necrotic material, similar to that described by Symmers and Valteris (1950); in no case is this characteristically tuberculous, and in one specimen a tuberculoid reaction is seen around remnants of the parasite. The structure of the post-mortem specimens is seen to be similar to that of the surgical specimens, though calcification was more common in the older patients of the post-mortem series; one half of these were calcified, usually beginning in the parasitic debris in the centre, but sometimes extending through the whole of the nodule.

\section{THE DOG TONGUE WORM}

(LINGUATULA SERRATA)

The Pentastomida (Linguatulida) are now usually regarded as a distinct class of arthropods (Mackie, Hunter, and Worth, 1954). The two species that are most frequently found in man are Armillifer (Porocephalus) armillatus, which is a relatively common human parasite in tropical Africa, and Linguatula serrata, recorded in man in temperate and tropical countries. The adult dog tongue worm ( $L$. serrata) lives in the nasal or paranasal sinuses of the animal; the male is approximately $2 \mathrm{~cm}$. in length, the female 8 to $10 \mathrm{~cm}$. in length. The ova are shed in the nasal secretions of the dog, and are ingested by an intermediate mammalian host, usually a herbivore, such as cattle, sheep, or rabbits. The fondling of an infested domestic dog allows ova to reach the fingers, and if the ova are ingested, the larvae hatch in the alimentary tract and emigrate through the bowel wall. The larvae usually encyst in the liver, spleen, or mesenteries, and undergo a succession of moultings during growth. The larva possesses a series of rings, each with a series of curved spines. The final development of the larva into the adult parasite is dependent on the larva reaching the nose of the definitive host. This can happen when a dog eats an infested rabbit, but in man the larvae usually perish; only small fragments of the parasite, or remnants of previous 


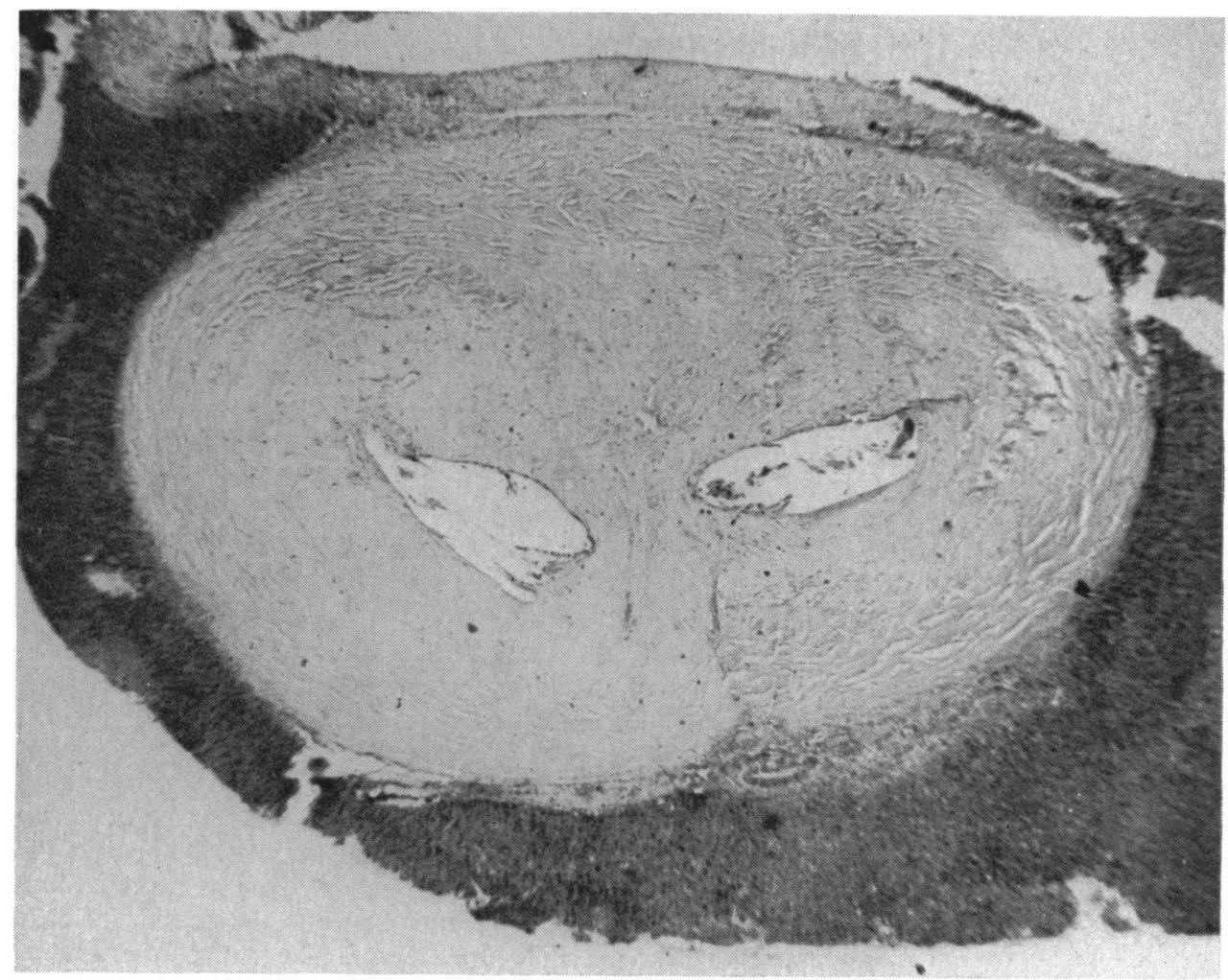

FIG. 1.

Case 1:

Fibrous

nodule with

crescentic

cavity, partly

lined by

multinucleate

giant cells.

Haemato-

$x y$ lin and

eosin $\times 35$.

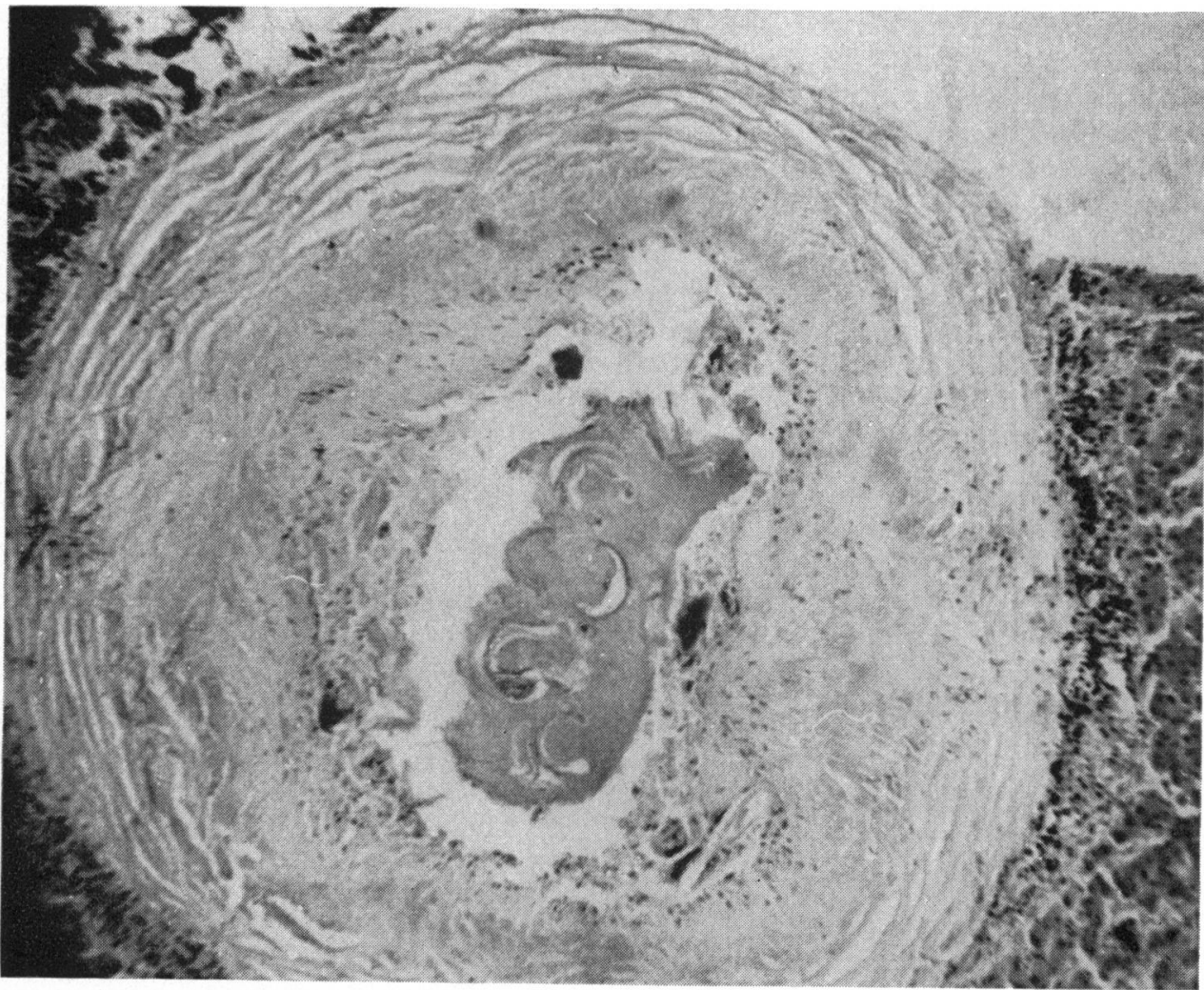

FIG. 2.

Case 3:

Fibrous

nodule with

parasitic

material,

including

curved hook-

lets, in the

central cavity.

Haemato-

$x y$ lin and

eosin $\times 60$. 
moults, together with the fibrous nodule, persist after the larva has died. At this stage the fibrous dead larval nodules tend to calcify.

Larval infestation in the liver of man was first described by Zenker (1854), and was widely recognized by German pathologists earlier this century. Aschoff (1928) reported that up to $12 \%$ of livers were found to contain tongue worm larvae at necropsy; Sonobe (1927), also in Germany, found $3.2 \%$ of livers to be involved. In Great Britain the necropsy records of the London Hospital are reported (Symmers and Valteris, 1950; editorial comment) to contain 38 instances, most of which were recorded before the first World War. I have observed at necropsy 19 instances of tongue worm larvae in the liver and spleen of 12 patients, together with a number of indeterminate nodules, probably of similar parasitic origin. This represents a minimal incidence of approximately $0 \cdot 4 \%$ (3,000 necropsies). In a number of these patients, all of whom died in the greater London areas, there was no history of residence outside this country.

In Britain, dogs carrying adult tongue worms have been described by Pillers $(1925,1929,1932)$ and Symmers (1956). Sinclair (1954) found living tongue worm larvae in 30\% (England), $50 \%$ (Scotland), and $70 \%$ (Northern Ireland) of slaughtered cattle. The contamination of pasture with tongue worm ova must occur in Britain, and although the fox is incriminated as a definitive host by Griffiths and Sinclair (1953) in Northern Ireland, and by Pullar (1936) in Australia, the dog is the most likely host for the infestation of man, especially in urban areas.

\section{THE DOG ROUND WORM}

(TOXOCARA CANIS)

The dog round worm ( $T$. canis) is smaller than the human round worm (Ascaris lumbricoides), being about $8 \mathrm{~cm}$. long in its adult form. Toxocara canis is the commonest intestinal parasite of dogs, puppies being infested by prenatal larval invasion of the placenta; these larvae migrate through the lungs of the newborn puppy to reach the trachea and the intestinal tract where they develop into adult worms. Eggs are excreted into the faeces in large numbers until the puppy is about six months old, when the adult worms die. If adult bitches ingest the ova, the larvae may remain in their tissues for some time, and subsequent placental transfer to developing puppies takes place in utero. Dogs throughout the world have been reported to be infested with Toxocara. In Wales, Lewis (1927) found T. canis in $16 \%$ of dogs and T. cati in $62 \%$ of cats; Brown and Stammers (1922) demonstrated round worm ova in $3 \%$ of faecal deposits in London streets. Human infestation with Toxocara cat $i$ has not been definitely established, and whilst this may take place, Sprent and English (1958) consider that cats are less dangerous because they become involved later in life than puppies and because they commonly bury their faeces.

Children are at greatest risk of ingesting ova from puppies, and although the larvae migrate through the tissue to reach the eye and other viscera they do not mature, and egg-laying adult worms are not found in the human intestine (Dent, Nichols, Beaver, Carrera, and Staggers, 1956). Widespread invasion of the viscera, especially of the liver and lungs, results in the formation of multiple minute granulomata. The importance of localized Toxocara granulomata and diffuse larval invasion is discussed later; it is only recently that these have been recognized to be of clinical significance.

\section{DISCUSSION}

The fact that parasitic granulomatous nodules can regularly be found in the livers of patients in the London area need not be due to immigration, foreign travel, or an increase in the number of dogs carrying the adult worm. The rarity of reported examples of dog tongue worm larvae in Britain is probably due to the paucity of identifiable parasitic material in the fibrotic nodule, and the absence of eosinophilia or other evidence of a parasitic origin. Provided this possibility is kept in mind, parasitic granulomata can be recognized, though larval nodules on the surface of the liver may be mistaken on naked-eye examination for other processes, usually fibrotic or calcified tubercles and angiomata. The specimen reported by Symmers and Valteris (1950) (case 2) in the liver of a girl of 17 who had died of tuberculosis was first thought to be a fibrous tubercle. Localized biliary fibro-adenomatous nodules are also found beneath the capsule of the liver, and these can often only be identified with accuracy by histology. Although one larval nodule was found in most of the livers examined, one surgical patient (case 4) and eight of the necropsy cases had multiple larvae, and these have been found in the liver, spleen, pancreas, mesenteries, and mesenteric lymph nodes. These patients indicate that a generalized peritoneal dissemination may occur, with the possibility of widespread abdominal symptoms. A single instance of a tongue worm larva in the prostate has been reported by Symmers (1957).

The macroscopic appearance of the hepatic nodule can be sufficiently characteristic to be diagnostic. It is often in, rather than under, the capsule of the liver, and is nearly always smooth, spherical or 
ovoid, commonly a few millimetres in diameter, but occasionally up to $1 \mathrm{~cm}$. in size. The consistency is very firm, and it may feel like a shot-gun pellet; the presence of calcium may not be demonstrable until the nodule is incised, but if calcium can be felt a larval nodule is probable and secondary carcinoma can be discounted. If the nodule is excised it should not be bisected in the operating theatre because a definite histological diagnosis is dependent on the demonstration of residual parasitic material; as this is usually very small in amount, it is unlikely to be found unless the specimen is processed whole in the laboratory. These fibrotic larval nodules in the human liver have been found to contain fragmentary dead parasitic material, and this inactivity would account for the rarity of an eosinophilic cellular reaction; it seems improbable that these larvae contain sufficient antigenic material at this stage to be able to produce a generalized allergic reaction.

The presence of a larval granuloma can best be established by the recognition of the gross and microscopic structure of the nodule. Pentastomiasis has been suspected clinically by the presence of eosinophilia and pyrexia in a patient in Vietnam (Dollfus and Canet, 1954) but the infestation in this case was due to the ingestion of living lizards, a form of therapy practised for respiratory diseases. Calcified larvae of tropical Linguatulids have been demonstrated by radiology (Wymeersch and Wanson, 1955), but in England discrete foci of calcification are likely to be due to calculi or to other causes such as pancreatitis. Radiology was limited by the absence of calcification in three of the surgical specimens and only half the post-mortem specimens were calcified. It may be anticipated that larval granulomata will not be radio-opaque while the parasites are viable or active, and radiology will be negative at the time that the larvae are most likely to cause clinical symptoms. In countries where histoplasmosis is endemic multiple foci of calcification in the spleen and, to a lesser extent in the liver, have been reported (Schwarz, Silverman, Adriano, Straub, and Levine, 1955); histoplasmalike organisms were demonstrated by special stains in calcified nodules in the spleen, liver, and lungs of patients dying in Ohio, United States of America (Okudaira, Straub, and Schwarz, 1961). The histological appearance of calcified histoplasmosis has features in common with that of old larval granulomata, but the hepatic histoplasmosis nodules of Okudaira et al. were all associated with splenic and pulmonary disease; a number of hepatic nodules of uncertain origin have been encountered during the present study, and although no histoplasma-like organisms have been seen, they have been excluded from the present series.
The recent recognition of Toxocara larvae as a cause of localized granulomata in the retina (Nichols, 1956; Duguid, 1961a, b) and the syndrome of 'visceral larva migrans' in American children (Beaver, Snyder, Carrera, Dent, and Lafferty, 1952) indicate that Toxocara larvae can be widely disseminated throughout the body. Nematode larvae have not been identified with certainty in extraocular tissues in Great Britain, but it is improbable that the eye is solely involved, and a typical clinical case of visceral larva migrans has been reported by Dickson and Woodcock (1959). The recognition of Toxocara larvae is difficult or impossible in sections of fibrotic inactive nodules, and it is possible that Toxocara larvae are a cause of sclerotic parasitic nodules in the liver that have no identifiable features of Linguatulid larvae (Case 4).

Although these parasitic larvae have in the past been thought to be symptomless and of no clinical significance, this may not be true. They must be considered when small hepatic nodules are found at laparotomy, since they can mimic metastatic carcinoma; if multiple they may prejudice the surgeon against radical surgery, and the occasional case of apparent hepatic carcinomatosis found at laparotomy and followed by long survival can be due to parasitic disease. In one of the cases described here it is possible that symptoms of gall bladder disease were due to a Linguatulid larva; in case 3 and the surgical Linguatulid larva reported in this country by Symmers and Valteris (1950, Case 1), the larval nodules were close to the gall bladder site, and both gall bladders were histologically normal. In case 4 the multiple parasitic larvae may have contributed to the symptoms ascribed to peptic ulceration or pancreatitis. No anti-parasitic therapy was given to these two patients, though the surgical patient of Symmers and Valteris was treated empirically with neoarsphenamine.

It is suggested that if fibrotic nodules are found at laparotomy in the liver or other viscera of patients with upper abdominal symptoms, they should be excised for histological examination; in this way it may be possible to determine if Linguatulid or other larvae are a cause of clinical symptoms.

I am indebted to the surgeons of Central Middlesex Hospital for their help and for permission to publish clinical details.

\section{REFERENCES}

Aschoff, L. (1928). Pathologische Anatomie, pt. 2, p. 901. Fischer, Jena. Ashton, N. (1960). Larval granulomatosis of the retina due to Toxocara. Brit. J. Ophthal., 44, 129-148.

Beaver, P. C., Snyder, C. H., Carrera, G. M., Dent, J. H., and Lafferty, J. W. (1952). Chronic eosinophilia due to visceral larva migrans. Pediatrics, 9, 7-19.

Brown, H. C., and Stammers, G. E. F. (1922). Observations on canine faeces on London pavements. Lancet, ii, 1165-1167. 
Dent, J. H., Nichols, R. L., Beaver, P. C., Carrera, G. M., and Staggers, R. J. (1956). Visceral larva migrans. Amer. J. Path., 32, 777-803.

Dickson, W., and Woodcock, R. C. (1959). Visceral larva migrans. Arch. Dis. Childh., 34, 63-67.

Dollfus, R. P., and Canet, J. (1954). Sur un Pentastomide: raillietiella hemidactyli. M. L. Hett 1934. Bull. Soc. Path. exot., 47, 401-408.

Duguid, I. M. (1961a). Chronic endophthalmitis due to Toxocara. Brit. J. Ophthal., 45, 705-717.

- (1961b). Features of ocular infestation by Toxocara. Ibid., 45, 789-796.

Griffiths, R. B., and Sinclair, K. B. (1953). The fox as a reservoir of Linguatula serrata in Great Britain. Trans. roy. Soc. trop. Med. Hyg., 47, 5.

Lewis, E. A. (1927). A study of the helminths of dogs and cats of Aberystwyth, Wales. J. Helminth., 5, 171-182.

Mackie, T. T., Hunter, G. W., and Worth, C. B. (1954). A Manual of Tropical Medicine, 2nd ed., p. 652. Saunders, Philadelphia and London.

Nichols, R. L. (1956). The etiology of visceral larva migrans. J. Parasit., 42, 349-362 and 363-399.

Okudaira, Masahiko, Straub, M., and Schwarz, J. (1961). The etiology of discrete splenic and hepatic calcification in an endemic area of histoplasmosis. Amer. J. Path., 39, 599-611.

Pillers, A. W. N.(1925). Linguatula serrata, Froblich 1789, in the nasal cavity of a bull bitch. Vet. J., 81, 126-130.

- (1929). Linguatula serrata in the nasal cavity of a dog. Ibid., 85, 307-309.
Pillers, A. W. N. (1932). Notes on parasites in 1931. Vet. Rec., 12 (new series), 898-899.

Pullar, E. M. (1936). A note on the occurrence of Linguatula serrata (Fröhlich, 1789) in Australia. Aust. vet. J., 12, 61-64.

Schwarz, J., Silverman, F. N., Adriano, S. M. Straub, M., and Levine, S. (1955). The relation of splenic calcification to histoplasmosis. New Engl. J. Med., 252, 887-891.

Sinclair, K. B. (1954). The incidence and life cycle of Linguatula serrata (Fröhlich 1789) in Great Britain. J. comp. Path., 64, 371-383.

Sonobe, K. (1927). Uber Linguatuliden-Larven-Knötchen (sog. Pentastomen-Knötchen) der Leber des Menschen. Virchows Arch. path. Anat., 263, 753-768.

Sprent, J. F. A., and English, P. B. (1958). The large roundworms of dogs and cats-A public health problem. Aust. vet. J., 34, 161-171.

Symmers, W. St.C. (1956). Communication to the Pathological Society of Great Britain and Ireland (Manchester).

- (1957). Two cases of eosinophilic prostatitis due to metazoan infestation. J. Path. Bact., 73, 549-555.

- and Valteris, K. (1950). Two cases of human infestation by larvae of Linguatula serrata. J. clin. Path., 3, 212-219.

Wymeersch, H. van, and Wanson, M. (1955). La Porockphalose nymphale et son image radiologique. J. Radiol. Electrol., 36, 22-24.

Zenker, F. A. (1854). Ueber einen neuen thierischen Parasiten des Menschen (Pentatomum denticulatum Rud.). $Z$. rationelle Med., n.s., 5, 212-234. 